\title{
Delirio y estancamiento: nuevas configuraciones del pueblo provincial en dos novelas chilenas y argentinas contemporáneas ${ }^{*}$
}

\author{
Delirium and Stagnation: New Compositions of the Provincial \\ Town in Two Contemporary Chilean and Argentine Novels'
}

\author{
CONSTANZA CERESA \\ JAMES SCORER \\ Universidad Adolfo Ibañez, Facultad de Artes Liberales, Departamento de Literatura \\ constanza.ceresa@uai.cl
}

School of Arts, Languages and Cultures, University of Manchester

james.scorer@manchester.ac.uk

En los últimos años, los imaginarios culturales argentinos y chilenos se han volcado con mayor regularidad al lugar de la provincia y / o el interior. En este artículo ubicamos dentro de esta tendencia a dos novelas contemporáneas ambientadas en la década de 1990, La descomposición (2007) del escritor argentino Hernán Ronsino y Niños extremistas (2013) del chileno Gonzalo Ortiz Peña, con el fin de explorar la configuración del espacio del pueblo provincial. En la historia cultural latinoamericana el pueblo ha ocupado tanto topográfica como simbólicamente un lugar liminal entre la ciudad y el campo. Su violencia inherente, ya sea constructiva o destructiva, desafía, entre otras cosas, la estricta dicotomía entre civilización y barbarie que a menudo se ha utilizado para separar los espacios urbanos de los rurales. En este artículo exploramos la violencia constitutiva del pueblo en ambas novelas, y el modo en que los cambios productivos del paisaje propios del desarrollo neoliberal afectan los cuerpos y sus formas de vida en niveles insospechados. Mientras La descomposición condensa esa violencia al ritmo acompasado de vidas humanas y no humanas en decadencia, Niños extremistas libera esa violencia inherente a la velocidad desbordada de la destrucción festiva. Ya sea en diálogo con el canon prexistente de una literatura del interior, o en el camino de lo improbable, ambas novelas abren la posibilidad de un nuevo corpus literario alrededor del espacio del pueblo.

Palabras claves: literatura, pueblos, violencia, neoliberalismo, paisaje productivo y afectivo.

In recent years Argentine and Chilean cultural imaginaries have (re)turned with increasing regularity to the locus of the province and/or the interior. In this article we locate two contemporary novels set in the 1990s - La descomposición (2007) by the Argentine writer Hernán Ronsino and Niños extremistas (2013) by the Chilean Gonzalo Ortiz Peña- within this trend by analysing how they deploy the provincial town. The town has played an important role in the (cultural) history of Latin 
America, occupying both a topographically and symbolically liminal place between the country and the city. The violence inherent to these towns (whether constructive or destructive) challenges, among other things, the strict dichotomy of civilization versus barbarism that has often been used to separate rural from urban spaces. In this article we explore the constitutive violence of the town in both novels, in which changes in the landscape affect both bodies and ways of life in unexpected ways. While La descomposición incorporates that violence into the measured rhythms of human and non-human lives that are decaying, Niños extremistas turns that inherent violence into the boundless pace of festive destruction. Whether in dialogue with a pre-existing canon of a literature of the interior, or via an exploration of the implausible, both novels open up the possibility of a literary corpus around the figure of the town.

Key words: literature, towns, violence, neoliberalism, productive and affective landscapes.

\section{INTRODUCCIÓN}

El espacio de la provincia se ha transformado en un escenario predilecto de la imaginación literaria chilena y argentina de las últimas dos décadas. ${ }^{1}$ Ya sea a través de personajes urbanos que llegan a un pueblo desconocido o regresan al propio, de relatos sobre la cotidianeidad local, o narraciones de viajes que conectan ambos espacios, estas obras literarias posan los sentidos en la geografía física y humana de estos espacios en un diálogo crítico tanto con las políticas económicas del presente como con las cosmovisiones del imaginario nacional en torno al territorio.

Dentro de la historia cultural latinoamericana, el espacio de la provincia ha tenido una carga simbólica sustancial para la identidad de la nación. Para Domingo Faustino Sarmiento la provincia o el interior (que vinculaba principalmente a la pampa argentina) era un territorio cuya extensión barbárica debía organizarse con cultura. Asimismo, las obras regionalistas de finales del siglo XIX y principios del siglo XX tendieron a representar la vida del hombre en su lucha con un medio natural hostil, lucha que le daba "un carácter original, primitivo y épico" (Latorre 1953: 76). Sin embargo, las narrativas actuales han tendido a desafiar estas dicotomías estructurales de la nación, abriendo otras zonas intermedias con

\footnotetext{
${ }^{1}$ Algunos ejemplos de obras actuales escritas y creadas en provincia de las últimas dos décadas: Matilde Sánchez (El desperdicio) Hernán Ronsino (su trilogía), Federico Falco (Flores nuevas), Selva Almada (El viento que arrasa), Samanta Schweblin (Distancia de rescate), Romina Paula (Agosto), Inés Acevedo (Una idea genial), Iosi Havilio (Opendoor), entre otros narradores argentinos. Además de la poesía de Sergio Raimondi, Diego Colomba, Mercedes Araujo, entre otros. Asimismo, el cine de Lucrecia Martel, Lisandro Alonso, Pablo Trapero, Marian Linás, Albertina Carri, entre otros, también ocurren en la provincia. En Chile, se encuentran las novelas de Alvaro Bisama (Ruido), Diego Zúñiga (Racimo), Lina Meruane (Fruta podrida), Leonardo Sanhueza (El año del perro), Gonzalo Ortiz (Los niños extremistas), Marcelo Mellado (La provincia) o la poesía de Mario Verdugo (La novela terrígena), Gloria Dünkler (Spandau), entre otros. Muchos ejemplos hay en el cine chileno con las obras de José Luis Torres Leiva (El viento sabe que vuelvo a casa), Alejandro Fernández (Huacho, Sentados frente al fuego, Matar a un hombre), Alicia Scherson (Turistas); Dominga Sotomayor (La isla).
} 
el que pensar estos espacios fuera de la urbe. En su estudio Buenos Aires y las provincias. Relatos para desarmar, Laura Demaría (2015) propone pensar la provincia fuera de una lógica binaria ciudad/centro v/s provincia/periferia, y considerarla, más bien, como una herramienta crítica que considera los modos en que el territorio nacional (en particular el argentino) ha sido distribuido y jerarquizado desde el siglo XIX hasta la actualidad. Esto implica enfocarse en el movimiento y desplazamiento que conectan e intersectan ambos espacios y desestructura el archivo de las narrativas nacionales. De ese modo, la provincia puede ser entendida como un lugar discursivo que se sitúa "entre" el imaginario nacional "porteńo-céntrico" y el regionalismo de color local: "Escribir en provincia se sale de la referencia al color local, del binarismo y se abre a la 'zona' como se lee en Saer, una máquina de narrar donde los gestos, los textos, las tonadas, las prácticas culturales se dispersan y acontecen como espectros de una escritura que se vuelve estar, lugar de enunciación que articula un tiempo condensado y no sucesivo" (Demaría 2015: 426). Así, continúa Demaría, la escritura en provincia "no es una cuestión de geografías, es un dispositivo, un modo de mirar, leer y escribir que inscribe aperturas en el archivo" (Demaría 2015: 493). ${ }^{2}$

Siguiendo esta reflexión, y para efectos de este ensayo, tomaremos la provincia como un dispositivo y lugar de lectura que se sitúa "entre" binarismos espaciales. ¿¿De qué forma estas obras escritas en provincia desestructuran el archivo de las representaciones simbólicas del territorio nacional, y particularmente del espacio del pueblo chico? En primer lugar, habría que preguntarse cuáles son las condiciones que han provocado el retorno a las ficciones escritas en provincia en tiempos de globalización. Para Lucía De Leone, esta vuelta "coincide, en los planos político, social y económico con un momento en el que el campo se afirma como un foco de interés, de disputa entre sectores, y en materia productora de nuevos relatos; y en el plano cultural, con un conjunto de especulaciones teórico-críticas que se interrogan sobre el estado del arte del presente" (De Leone 2016: 188). Si nos detenemos en el espacio del campo argentino, esto es en el interior rural, no parece coincidencia que gran parte de esta producción artística haya emergido en un momento particularmente tenso de la relación entre Buenos Aires y el interior, aguzando los efectos de la crisis del 2001. La decisión de Cristina Fernández en 2008 de subir las tarifas a ciertos productos agrícolas produjo confrontaciones entre los dueños de la tierra y el gobierno. Con el "conflicto del campo" todo el país, incluyendo la capital, fue escenario de marchas y diversas expresiones de apoyo a los pequeños productores, mientras el monocultivo de la soya desplazaba poco a poco la postal del campo argentino de extensos campos verdes con vacas pastando libres. En el caso chileno, la acelerada transformación del paisaje rural productivo se remonta a

\footnotetext{
${ }^{2}$ En una exploración más detallada sobre la literatura provincial en la Argentina y Chile excede los límites del presente trabajo, valdría la pena preguntarse hasta qué punto escritores anteriores a los mencionados en la nota 1, como Antonio Di Benedetto, Héctor Tizón, Daniel Moyano, Jorge Riestra, Haroldo Conti, Juan José Hernández, o Juan José Saer, entre otros, cuyas obras eluden la pura referencialidad, el documentalismo, el pintoresquismo, el folklorismo y el costumbrismo en sus evocaciones al interior argentino (Prieto 2006: 351352), también escribían en provincia. La misma pregunta podría hacerse a una novela chilena como Casa de campo (1978) de José Donoso.
} 
1974 con la puesta en vigencia del decreto Ley 701, un sistema de incentivo estatal para la plantación forestal privada, reemplazando los cultivos de trigo, legumbres y bosques nativos por miles de hectáreas de pinos y eucaliptus. El efecto avasallante del monocultivo se comenzó a sentir hace algunos años con los problemas de sequías e incendios, por una parte, como también en el plano de las relaciones laborales coordinadas por empresas transnacionales que tienden a eliminar la noción de comunidad e identidad de trabajo local. Por otra parte, la privatización de los recursos naturales como el agua ha provocado un estado de precariedad en los pueblos aledaños a mineras e hidroeléctricas, afectando también territorios de valor ancestral. Todo esto, sumado al uso de agrotóxicos y pesticidas, ha transformado el espacio rural en un territorio amenazante, que afecta las formas de vida y de muerte de los pueblos que se nutren de estas actividades. ${ }^{3}$

Aunque en este trabajo usamos el término provincia para desmantelar la dualidad entre metrópolis y periferia, es importante destacar que una serie de topografías variadas confluyen en este término: interior, paisaje rural, campo tecnificado, pampa, desierto, pueblo, entre otros. Estos términos aúnan diversos significados vinculados tanto a grandes centros urbanos como a expansiones de tierra no habitada. Pero los diversos asentamientos localizados en el interior argentino y chileno son mucho más complejos en términos de redes tecnológicas, estructuras sociales e identidades culturales que lo que se desprende de estos términos. Por lo tanto, la elección de dos novelas que transcurren en pueblos chicos es deliberada, pues nos permite desestabilizar la idea establecida de que son lugares estancado en el tiempo, un grillete barbárico puesto en el trabajo civilizador de la nación o un idilio romántico que ofrece un retiro pre-moderno de la metrópolis.

$\mathrm{Si}$ nos centramos en los imaginarios construidos en torno a la provincia en siglos anteriores, es posible apreciar su presencia espectral en las obras actuales, y en particular, en las obras que este ensayo analizará. Entre las muchas aristas por las que se pueden abordar estas obras escritas en provincia -o, en este caso, también en el pueblo-, tanto en Chile como en Argentina, este artículo se centrará en dos novelas contemporáneas La descomposición de Hernán Ronsino (2007) y Los niños extremistas de Gonzalo Ortiz Peńa (2013), cuyos relatos están situados en el espacio del pueblo chico durante los años noventa. Considerando que el pueblo chico ocupa un lugar liminal entre la ciudad y el campo y las significaciones culturales que conllevan, se explorará de qué manera los cambios productivos del paisaje afectan los cuerpos y sus formas de vida en niveles de violencia insospechados. Mientras $L a$ descomposición condensa esa violencia al ritmo acompasado de vidas humanas y no humanas en decadencia, Niños extremistas libera esa violencia inherente a la velocidad desbordada de la destrucción festiva. Ya sea en diálogo espectral con el canon, o en el camino de lo improbable, en ambas novelas hay una reflexión en torno a una literatura posible en torno al pueblo.

\footnotetext{
${ }^{3}$ La novela Distancia de rescate (2014) de la argentina Samanta Schweblin aborda el efecto de los agrotóxicos en los campos de soja y la novela de la chilena Lina Meruane Fruta Podrida (2007) trata de los pesticidas en la exportación de manzanas, haciendo un paralelo con el cuerpo enfermo. Ambas narraciones distópicas crean una atmósfera cercana a la ciencia ficción.
} 


\section{LA DESCOMPOSICIÓN}

La primera novela de Hernán Ronsino, La descomposición, publicada en 2007, es parte de una trilogía compuesta por Glaxo (2009) y Lumbre (2013), todas ambientadas en Chivilcoy, un pueblo de unos 55.000 habitantes aproximadamente, a $150 \mathrm{~km}$ al oeste de Buenos Aires. La novela, dividida en dos secciones, "La acidez del limón” y "Esa podredumbre", relata las experiencias recientes del narrador, Abelardo Keiffer, quien invita a su único amigo Bicho Souza a un asado para celebrar su cumpleaños de sesenta. La narrativa del presente se interrumpirá con eventos recordados y relatados por los dos, tanto como por episodios que tienen que ver con la historia del pueblo y por prefiguraciones de posibles futuros.

La pampa es uno de los paisajes más relevantes del imaginario nacional fuera de la ciudad. Los mapas y planes que organizaron el futuro del diseño urbano se basaron en un borramiento violento de los ciclos, prácticas y culturas de la tierra, además de convertir el interior en un espacio vacío. Como lo describe Graciela Montaldo, el interior era un espacio de "extensión, soledad, inseguridad, resignación ante la muerte violenta", que para Sarmiento había que cartografiar, conectar con una infraestructura nacional y poblar con cultura (Montaldo 2010: 10). La referencia de Montaldo a la "extensión" del espacio es importante, ya que destaca la tensión que reside en casi toda la literatura sobre la pampa, y que entiende la frontera como límite que se traspasa constantemente. Escribir sobre la pampa implicaba entonces una intervención violenta y tenía la intención de superar las extensiones enormes del interior $y$, a la vez, la violencia asociada con esta.

Para Ronsino narrar el interior argentino constituye un gesto a la vez literario y político, una forma de construir una literatura nacional que no sólo se ocupe de Buenos Aires (Friera 2007). Es como si su trabajo fuera una respuesta a la frustración de Daniel Moyano, evidente en su prefacio al libro de Juan José Hernández, La señorita Estrella y otros cuentos, donde sugiere que los escritores del interior argentino históricamente estuvieron atascados entre "un folklorismo mentiroso que no compartíamos, apoyado más en el paisaje que en el hombre" y en "una cultura ciudadana que venía de Buenos Aires, vía radial, a la que, lo sabíamos muy bien, no pertenecíamos. [...] Lo gauchesco inmediato - y falso -, al menos a mí me desesperaba” (Moyano 1987). La descomposición, en ese sentido, es una novela autorreflexiva, que relata una historia sobre Chivilcoy y al mismo tiempo las dificultades de abordar ese pueblo en la literatura. Abelardo recuerda, por ejemplo, cómo su amigo Pajarito Lernú reflexiona sobre la historia literaria de Chivilcoy durante una de las excursiones semanales al hospital psiquiátrico donde Pajarito vive, haciendo una comparación entre la historia de Mauricio Birabent sobre Chilvilcoy, El pueblo de Sarmiento, y Pago Chico de Roberto Payró, una colección de cuentos sobre un pueblo no-nombrado de las pampas (Ronsino 2007: 52). La referencia al libro de Payró nos recuerda que la novela de Ronsino no sólo trata de Chivilcoy, sino también de otros pueblos similares que forman parte del interior argentino. Pajarito Lernú, con su lúcida demencia, demuestra la tensión entre una historia cuyo sentido está clausurado, al estilo de Birabent, y las ficciones de Payró que dejan la historia abierta a reinterpretaciones constantes. Eso, agrega Pajarito, es 
"el atributo revolucionario de la literatura, amplificar de sentido los relatos, crear nuevos mundos" (Ronsino 2007: 53). En el comentario de un blog publicado en 2011 donde se refiere con detalle al texto de Birabent, Ronsino sostiene que El pueblo de Sarmiento ubica a Chivilcoy dentro de una tradición liberal, es decir, como parte del empuje hacia la civilización. También argumenta allí que Birabent elige la ficción como una forma de llenar los huecos de la historia, lo que otorga a su libro otra dimensión. Ronsino retoma justamente la ficción para escribir una novela que no sólo trastoca la visión de Sarmiento (y de Birabent) sobre Chivilcoy como modelo de la civilización racional (cit. en Friera 2007), sino también desafía la dicotomía sarmientina civilización/barbarie.

La descomposición está habitada entonces por diversas voces narrativas que relatan el pasado de forma variable. La voz narrativa principal reconoce las incertidumbres inherentes al esfuerzo de capturar el pasado ("toda foto, se me ocurre, retrata un rostro imposible, dibuja en el presente un rostro perdido" (Ronsino 2007: 39)) y advierte que éste se puede narrar de diferentes formas: "Bicho Souza está amasando, despacio, la mejor manera de evocar un recuerdo" (Ronsino 2007: 63). En la novela, la incertidumbre sobre el pasado es la base de la posibilidad narrativa, de la introducción de la política y del enfrentamiento de imaginarios establecidos sobre el interior argentino. Esa posibilidad contrasta con el relato oral de Lucio Montes, un personaje que invita unos tragos a quien esté dispuesto a escuchar la historia del Viejo Pujol, y cuenta la historia tantas veces que termina por volverla "su propia historia" (Ronsino 2007: 127). Las narraciones repetidas de Montes nos recuerdan cómo la novela ofrece una reflexión sobre la tensión entre rutina -las historias repetidas sin variación- y evento, una tensión inherente a la vida de pueblo pequeńo, construida con frecuencia a partir de ciclos reiterativos. Si se considera la dicotomía civilización-barbarie como una historia repetida dentro de la narrativa argentina, La descomposición sería entonces un intento de producir una ruptura dentro de esa repetición.

El epígrafe de la novela tomado del cuento de Juan Carlos Onetti "Bienvenido, Bob", ofrece una pista a la analogía entre hábito y envejecimiento. Ahí el narrador relata su esfuerzo (vano) de conquistar a Inés, la hermana de Bob, durante su juventud. En el momento de perderla, recuerda las palabras de Bob:

Estuvo diciendo que en aquello que él llamaba vejez, lo más repugnante, lo que determina la descomposición, o acaso lo que era símbolo de descomposición era pensar por conceptos, englobar a las mujeres en la palabra mujer, empujarlas sin cuidado para que pudieran amoldarse al concepto hecho por una pobre experiencia. Pero -decía también- tampoco la palabra experiencia era exacta. No habían ya experiencias, nada más que costumbres y repeticiones, nombres marchitos para ir poniendo a las cosas y un poco crearlas (Onetti 1999: 129).

El hecho de que la palabra que da el título a la novela de Ronsino aparezca en esta cita dos veces enfatiza la importancia de esta conversación. Lo que Bob demuestra es precisamente lo que Bicho Souza y Abelardo Keiffer tienen que confrontar: la manera en 
que la rutina condiciona los modos de ver el mundo en la vejez. Es por eso que cuando Bicho Souza le cuenta a Abelardo cómo se siente al acompañar a Josefina a la sala de bingo, su narrativa se desarrolla alrededor de las frases "se desacostumbra" y "se acostumbra" (Ronsino 2007: 54).

Asimismo, la tensión entre rutina y ruptura se expresa en el plano formal de la novela, con el uso de la repetición como recurso estilístico recurrente. Varias frases e imágenes se repiten en el libro, como por ejemplo "viene del fondo" (Ronsino 2007: 13; 47) o la personificación de la noche como un animal. Esa repetición se conecta con la idea tradicional de que el tiempo corre más lento en el pueblo, y se vive como una suerte de estancamiento. Sin embargo, son justamente las diferencias pequeñas entre, por ejemplo, el comienzo del capítulo tres en la primera parte, como repetición del comienzo del capítulo uno, las que indican una diferencia entre cómo se narra la novela y cómo narra Lucio Montes. Si éste último siempre cuenta su historia favorita de la misma manera, "con los mismos detalles y ejemplos; nunca se permitió alterar algún dato, incorporar, si se quiere, alguna metáfora nueva, tal vez porque haciéndolo, Montes, creería que estaría faltando a la verdad" (Ronsino 2007: 128), el narrador de La descomposición sí deja lugar para la diferencia. El primer encuentro sexual entre el narrador y Silvia Ayala bajo el cielo nocturno está así estructurado alrededor de dos frases repetidas: "alguna vez" y "un cielo acribillado" (Ronsino 2007: 41-42). Pero esta última frase en particular se repite de distintos modos: "ese cielo", "un cielo acribillado", "del cielo acribillado de estrellas", "un cielo asî". De allí que, si la novela propone que la repetición es una forma del hábito, simultáneamente perturba la repetición con variaciones menores.

En otras palabras, las variaciones en la repetición ofrecen una posibilidad narrativa. Juan José Guerra nota en su lectura de la novela que mientras la escritura se destruye como parte del proceso de la "ruinación" (algunas letras de la cervecería no están), de la descomposición también emerge la posibilidad de la composición (Ronsino 2007: 90; 94). Sugiere así que las ruinas de la novela forman la base para una nueva poética formada por un collage de fragmentos múltiples que se pueden juntar y darle vida a una narrativa colectiva (Ronsino 2007: 94). Desde la perspectiva de la novela, los vínculos entre violencia y narración son una parte inherente de la historia argentina y del interior. En una reseña que escribe para el diario local, el joven José Tarditti dice: "La historia [...] más de las veces, se parece a un campo desierto manchado de sangre. La historia es potencia y dolor. Ese campo, desierto, la posibilidad; esa sangre, derramada, el dolor. Entre la esperanza y la violencia, se entreteje la historia" (Ronsino 2007: 90). La palabra "campo" aquí funciona como "campo de historia", pero también como "campo" en el sentido de "interior rural". Escribir es, entonces, un acto de violencia, negativo en el sentido que le dio Sarmiento quien inscribe su visión en la "tela vacía" del interior argentino (ese ya mencionado "campo desierto manchado de sangre" del cual habla Tarditti); pero también un acto positivo, una fuerza creativa que usa la violencia para darle vida a esa inscripción.

De esa manera, en La descomposición la violencia es entendida tanto como erupción como proceso paulatino de declive, condensada en su entorno material y natural. La 
violencia como erupción se manifiesta en los asesinatos, suicidios y accidentes mortales que ocurren en el pueblo a lo largo de la novela. Ronsino ha dicho al respecto que no cree que la violencia presentada en la novela sea inherente a la vida del pueblo: "no creo que esa violencia sea ontológica, sino que es una cuestión más humana, en un contexto social que excede al pueblo" (cit. en Friera 2017). Ese contexto social es justamente la década del noventa que determina una de las formas principales de la violencia en la novela: la violencia de la descomposición bajo la modernización neoliberal. En una entrevista Ronsino ha dicho que situar la novela en 1999 le permitió pensar la forma en que el país se desarmaba antes de la crisis del 2001, ya que dichas crisis se sienten en los pueblos provinciales antes que en la capital (Friera 2017).

Cuando Abelardo se niega a aceptar la oferta de su padre de manejar el negocio de la familia -la cervecería del pueblo-, rompe con la tradición generacional y condena a la compañía a seguir el mismo declive industrial del pueblo y de la nación. Es desde las ruinas de la fábrica que el narrador mira su casa vecina todavía sin terminar. Ahora haydice- dos casas "una real (abandonada) y otra posible (que ahora nunca llegará a ser real)" (Ronsino 2007: 123). Como bien sostiene Juan José Guerra, las ruinas del pueblo indican el declive del grupo socio-económico del narrador (el crítico nota también que el pueblo tiene la urbanización de Los Troncos, un barrio exclusivo, cuya construcción necesitaba de la destrucción de algunos edificios). En su opinión el tornado que pasa por el pueblo funciona como una metáfora del "torbellino de la historia, la marcha del progreso que no puede avanzar sin dejar escombros a su paso"; y como tal, sugiere que la novela de Ronsino es una reacción a la visión de Sarmiento sobre Chivilcoy, "una contranarrativa del progreso" (Ronsino 2007: 92).

En ese sentido la violencia muchas veces se hace inseparable de la historia particular del pueblo y su entorno. El narrador describe en detalle, por ejemplo, la expedición de caza durante la cual, a la edad de ocho ańos, mató sin querer a Eugenio Calderón, cuando el gatillo de su arma se trabó en el alambre que traspasaba (Ronsino 2007: 26). El impacto del alambre en la muerte de Calderón conecta el evento con la violencia asociada a este producto (el alambre) de fuerte presencia en el interior argentino, visto, por un lado, como un símbolo de la expansión civilizatoria (recuérdese la frase atribuida a Sarmiento " $i C e r q u e n$, no sean bárbaros!”), y por el otro, como símbolo de la ferocidad de la apropiación capitalista. El tren que pasa por el pueblo, un modo de transporte que se usaba para civilizar pueblos y conectarlos a las redes económicas nacionales, casi siempre se describe en la novela con imágenes violentas: "La luz de la locomotora nos alumbraba con fuerza" (Ronsino 2007: $32)$; "espantando a los animales, sacudiendo las chapas oxidadas de los ranchos" (2007: 66); "En verano el paso del tren se parece a la respiración de un boxeador herido" (2007: 67). El padre de Abelardo es miembro de una sociedad secreta que se junta en el pueblo con la intención de preservar su herencia aria, un recuerdo de los nazis que se exiliaron en el interior argentino después de la segunda guerra mundial. Y, de forma similar, el narrador juega a la violencia como cuando era niño y se enfrentaba a los indios en su imaginación (Ronsino 2007: 27), reproduciendo el imaginario de la conquista del interior. 
Además, y más allá de las siempre posibles interpretaciones alegóricas, tal vez la imagen más perdurable de la descomposición es aquella de la destrucción gradual que evocan las hormigas que se comen a la cucaracha bajo el asiento de Bicho Souza durante el asado. Las hormigas, dice el narrador, están a "un simple movimiento" de la aniquilación (Ronsino 2007: 40), una imagen que también propone que, a pesar de todo, la violencia y la descomposición alimentan otras formas de vida. Tal vez por eso el narrador decide enterrar el cadáver de su mujer, fallecida en un accidente casero, en la huerta de su casa. Como sugiere Beatriz Sarlo en su reseña de la novela, la ausencia de alguna prefiguración de su muerte es fundamental para entender la forma en que escribe Ronsino: "narrar [...] con dilaciones y desvíos, evitando que el impulso de la materia narrada (su interés) se lleve por delante la voluntad de fragmentar. En este sentido, La descomposición responde a su título: destruye deliberadamente la continuidad hasta descomponer la materia misma de la que está hecha" (Sarlo 2012: 29-30). De todos modos, hay algo en la forma prosaica en que se presenta la muerte y el entierro de la mujer que enfatiza la violencia en la novela como algo inherente, latente y familiar. Es como si el narrador intentara reintegrar la muerte violenta a la rutina de la descomposición. El cadáver de la cucaracha es, en ese sentido, metonimia del cadáver de la mujer, también sujeto a la descomposición.

Ronsino usa el lenguaje para desestabilizar el concepto de lo que significa ser humano. Lo humano-animal-objeto-paisaje coexisten como una red cambiante de imágenes y experiencias. Así los humanos son frecuentemente comparados a animales: "Bicho abre la boca, como un pescado"; "Dicen que la pendeja tenía cara de culebra" (Ronsino 2007: 116); "el Viejo Pujol, como un chancho" (Ronsino 2007:128). Montes cuenta el momento cuando ve al Viejo Pujol después de caer de su silla: "Berreaba. Ahí pensé otra vez en los chanchos, porque parecía que lo estaban carneando" (Ronsino 2007: 131). Y Bicho Souza, una presencia expansiva, muy corporal y conectada al mundo de los insectos por su nombre, dice de sí mismo que está "como si tuviera un animal agarrado, acá, en la panza, y me clavara las garras con la intención de salir" (Ronsino 2007: 31). En algún momento el narrador también sueńa que la liebre que mató cuando era chico durante una cacería lo muerde (Ronsino 2007: 113), como una inversión de la jerarquía de cazador/presa. En otros momentos hay además asociaciones entre animales y objetos: "La silla de paja [... parece un caballo viejo" (Ronsino 2007: 43); "Donde el timbre del teléfono, por ejemplo, insiste, monocorde, cada dos o tres segundos. Como si respirara" (Ronsino 2007: 45). La noche, en particular, es constantemente descrita como algo vivo, como un animal, una amenaza, una oscuridad ominosa que emana de la tierra y que rodea al pueblo: "Si la noche es un animal húmedo, que jadea, entre resquicios invisibles, ese animal tiene la boca de un lobo hambriento" (Ronsino 2007: 112); mientras un hombre: "se va perdiendo en la oscuridad de la ruta. Se va deformando, comido, de a poco, por la noche" (Ronsino 2007: 87). Estas asociaciones indican que la novela de Ronsino encaja dentro de la tendencia actual en la literatura argentina de producir, en palabras de Gabriel Giorgi, "textos en los que la distinción normativa -moderna y civilizatoria- entre lo humano y lo animal es desplazada por líneas de continuidad, contigüidad, pasaje y ambivalencia entre cuerpos humanos y animales" (Giorgi 2014: 29). De allí que la novela apele a una falta 
de interioridad subjetiva, donde los sujetos afectan y son afectados por lo que les rodea. El exceso de descripción y el paso lento de la narración se intensifica con el sobreuso de comas, creando un relato de respiración agitada. Estas u otras variaciones lingüísticas permiten crear una atmósfera en la cual el centro humano de las cosas se difumina.

Sarmiento creía que la poesía requería "el espectáculo de lo bello, del poder terrible, de la inmensidad, de la extensión, de lo vago, de lo incomprensible, porque sólo donde acaba lo palpable y vulgar, empiezan las mentiras de la imaginación, el mundo ideal" (cit. en Montaldo 2010: 11). Como postula Graciela Montaldo, el autor de Facundo construye así un sujeto que "se abisma en lo indeterminado, en el peligro y que subraya su diferencia" (Montaldo 2010: 12). Escribir se vuelve una forma de confrontar las tierras sin límite y la ley del interior argentino, una forma de "racionalizar-civilizar- esa zona de incertidumbre que es la naturaleza americana" (Montaldo 2010: 13). Ronsino, en cambio, con su texto escrito en provincia, abraza esa falta de definición - "la inmensidad del campo" (Ronsino 2007: 28) - y construye su narrativa alrededor de fronteras permeables. Es en ese gesto que Ronsino reutiliza críticamente formas heredadas de narrar el pueblo argentino y convoca ese imaginario para desplazarlo dentro de su imposibilidad.

\section{Niños EXTREMISTAS}

Sin descartar la importante influencia de las ideas de Sarmiento en la historia cultural argentina y continental, donde más se desarrolló el imaginario en torno a la provincia en Chile fue en la literatura criollista de principios de siglo XX, donde el campo o la hacienda jugaban un rol central. El agro chileno funcionó hasta avanzado el siglo bajo los valores de una sociedad premoderna, en la forma de un orden sagrado e inmutable que algunos historiadores han llamado "pax rural" (Salazar et al. 1999) o "subordinación ascética" (Bengoa 1988). Aquella especie de aislamiento de la zona rural de los grandes cambios sociales y culturales que sucedían "afuera" se mantuvo por muchos años. ${ }^{4} \mathrm{Al}$ tratar el conflicto latente entre las ilusiones oligárquicas de progreso y la cuestión social, la historiadora Sofía Correa afirma: "El letargo de los pueblos rurales respondía en parte al predominio centenario de la hacienda en cuanto sistema socioeconómico e instancia de poder político y social; en la práctica, ella canalizaba los intercambios de la sociedad rural con las ciudades más dinámicas, al tiempo que condicionaba poderosamente el curso de su vida" (Correa et al. 2001:27). Niños extremistas, publicada el 2013 por la editorial Sangría revierte esa pax rural y apaciguamiento con color dede los pueblos de provincia, con una gesta de impulsos rebeldes incontrolables. ${ }^{5}$

\footnotetext{
${ }^{4}$ Algo similar se aprecia en el relato autobiográfico en décimas de la folclorista y poeta Violeta Parra quien concibe el campo de su infancia como un espacio mítico de comunidad, pero a la vez de relaciones laborales opresivas.

${ }^{5}$ Otras narrativas chilenas recientes, como Valpore de Cristóbal Gaete, Valporno de Natalia Berbelagua o los libros de relatos de Cristian Geisse (En el regazo de Belcebú, El infierno de los payasos) juegan también con estos espacios distópicos.
} 
"Por eso me uní a la revuelta. Yo nunca había hecho nada. Nada...Fue Jim quien me propuso hacer la revolución” (Ortiz Peña 2013: 15). Así comienza la novela de Gonzalo Ortiz Peña, que relata el retorno de un joven estudiante de cine a su pueblo natal Penco, pueblo costero de 46.016 habitantes de la octava región de Chile, después de seis años estudiando en Santiago. Junto a sus amigos de infancia Jim, el poeta, y Ángelo, el extremista, sacudirán el letargo de la vida de pueblo provinciano a través de acciones terroristas acercándose al terreno del delirio violento y el goce que vemos en las novelas de César Aira o Washington Cucurto. A diferencia del ambiente contenido de La descomposición, en esta novela las pulsiones reprimidas brotan sin control, como pura fuerza destructiva que termina por romper con las leyes del status quo y de paso, con la verosimilitud narrativa. Si en la novela de Ronsino la lenta destrucción se condensa en la naturaleza y vida material, en diálogo crítico con los modos de narrar heredados, Niños extremistas apuesta por tomar el camino del desacato. Del estancamiento del pueblo chico surge la semilla de la rebeldía adolescente, alimentada por una pulsión violenta que en tiempos de reconciliación democrática parece algo anacrónica y políticamente incorrecta. Así, la novela de Ortiz libera la violencia solapada de la democracia y el neoliberalismo, a través del camino de la revolución anarquista.

Siguiendo el tópico del regreso a casa, la llegada del cineasta a su pueblo natal crea una ruptura en la rutina de aquellos que se han quedado, forzando a revisar el estado de las cosas. Por ciertas referencias dentro del texto, como la prohibición de la entrada de Iron Maiden a Chile, se puede identificar el ańo 1992 como el momento en que acontecen los hechos principales de la novela. Es el periodo de la transición a la democracia, luego de diecisiete ańos de dictadura, donde ya se sienten los primeros signos de pesimismo y descreimiento ante las promesas de la Concertación. La novela se divide en tres partes: "Los camiones y la ciudad", "Niños extremistas" y "Extremistas pencopolitanos". En la primera y la tercera, el cineasta narra en primera persona su regreso a Penco, con el fin de filmar un documental. Para entonces Penco, viejo balneario tradicional de la zona, conocido por su industria local de loza y el equipo de fútbol Club de Deportes Lozapenco, aparece como un pueblo invadido de camiones madereros de las forestales, su fábrica local se encuentra en decadencia, el servicio de ferrocarril cerrado y los barrios invadidos de subsidios habitacionales nuevos y desocupados: "Del periodo de esplendor del balneario, de sus hoteles y restoranes no quedaba nada en pie: solo más poblaciones, más plazoletas, menos pescadores, más clase media y más remodelaciones" (Ortiz Peńa 2013: 17). A lo largo de la novela se puede notar un tono de melancolía frente a los vestigios del pueblo antes de la dictadura, mayoritariamente edificios públicos derruidos, entre otros; y de rabia intachable frente una violencia estatal que ya no es explícita, sino que proviene mayoritariamente de su alianza con el mercado, ese enemigo invisible y ubicuo que modela las formas de vida.

La llegada del cineasta tiene en un comienzo algo de épico y poético que glorifica la marginalidad adolescente y su estética:

Vueltas y vueltas llevaron mis pasos a oír que las olas se sucedían una tras otra y ahí, frente al inmenso mar, los fui a encontrar. Caminaban por la orilla sombría 
y despiadada del océano, cerca de un tronco arrojado por las mareas del crudo invierno que se iba. Vestían chaquetas de mezclilla, chalecos, camisas leñeras, jeans y pantalones de cotelé. Calzaban zapatillas y bototos de seguridad. Fumaban cigarrillos baratos (Ortiz Peña 2013: 16)

Desde las primeras páginas, las acciones de la novela se van desenvolviendo vertiginosamente. El mismo día del reencuentro, el cineasta y Ángelo, el extremista, ya han derribado una torre de alta tensión con una facilidad poco creíble, para seguir planeando actos destructivos contra el sistema, reviviendo una rabia infantil nacida en tiempos de represión. La segunda parte está relatada por el poeta Jim en estilo epistolar, que proviene de un cuaderno clandestino escrito a sus catorce años dirigido a sus "camaradas" lautaristas, quienes guardarán su diario en la cabaña del bosque junto al arsenal de armas. El relato del poeta reconstruye el inicio de la amistad entre los tres nińos en pleno periodo dictatorial, su vida escolar, la participación en las protestas contra el régimen, sus andanzas en barrios marginales y su actitud anárquica frente al deber ser, ya sea de izquierda o de derecha. Ya en la tercera parte los actos violentos se desencadenan con una velocidad febril: asalto al Banco del Estado, balaceras, fiestas, peleas y persecuciones hasta un desenlace improbable.

Niños extremistas está saturada de bajadas discursivas anárquicas en torno a la política actual, entre otros temas, que bordean el lugar común del panfleto adolescente. Algunos personajes de culto que se mencionan son ciertos pensadores "extremistas" como Albert Camus, Karl Marx y Bertolt Brecht, entre otros, junto a la poeta Gabriela Mistral y Jorge Luis Borges, al tanto que dejan en claro su rechazo al poeta comprometido Pablo Neruda, aunque todo en un tono cercano al cliché panfletario. Si en La descomposición nos encontramos con periodistas, críticos y cronistas que reflexionan sobre la (im) posible representación del pueblo argentino y particularmente de Chilvicoy, la dimensión autorreflexiva de la novela de Ortiz Peńa se centra más bien en la escritura como forma de violencia, tanto hacia el status quo como hacia el lector, al poner en entredicho las bases de la verosimilitud narrativa a partir del improbable sacudimiento del letargo pueblerino, con ciertas resonancias a los niños perversos y vagabundos del surrealismo que se mueven fuera de la ley. Así lo expresa el cineasta en la última página de su cuaderno, al no poder imaginar el guión de su documental: "Escribir es inventarse una vida. Escribir es estar solo. Escribir es seguir siendo marginal. Escribir es atacar. Escribir es una marcha. Escribir es una marcha contra la envidia y la mentira. Escribir es defenderse. Escribir es odiar. Escribir es querer. Escribir es entender" (Ortiz Peña 2013: 115).

Dentro del mismo fervor adolescente se puede reconocer la mirada crítica de Ortiz Peña hacia la narrativa de los noventas, donde las obras solían seguir los parámetros de lo políticamente correcto y el imaginario de la lucha armada se había vuelto un tema tabú. Niños extremistas habla de los tiempos de transición en pleno 2013, lo que implica una suerte de intervención retroactiva de la historia desde el presente. Tal como afirma Patricia Espinosa, la novela apunta a "reelaborar la historia nacional de la derrota desde una minúscula gesta, cargando con un aura de heroísmo a sus personajes en medio de un 
tiempo que parecía ser sólo fracaso en la lejana provincial" (2017). En ese contexto, el autor se desmarca del tono melancólico de relatos de la infancia en dictadura predominantes en la nueva narrativa chilena, tales como en las novelas de Alejandro Zambra, Álvaro Bisama o Nona Fernández cuyos protagonistas infantes son testigos de la violencia y viven bajo el velo de lo que se omite. ${ }^{6}$ Niños extremistas es una novela de la infancia, sí, pero de una infancia de acción subversiva, irresponsable e imposible, que se mueve fuera del espacio de la familia y el espacio privado. A su vez, frente a la ausencia de discurso político y la predominancia de relatos mínimos en la literatura contemporánea, Niños extremistas abusa de los discursos panfletarios y las proclamas de jóvenes enrabiados ante el sistema, creando una épica de la lucha marginal contra el conformismo y la represión que parece, sin duda, anacrónica y estereotipada en el presente. El estereotipo se extiende también a los tipos de personajes: un cineasta, un poeta y un extremista, mostrando la dimensión creativa de la violencia en un mundo que ocurre a las sombras de un pueblo domesticado:

Tengo recién diecinueve años de edad y la dictadura ha terminado en los papeles, no en la práctica. La democracia aquí es aparente, fingida, postiza. A través de la noche veo las sombras de los muchachos vagabundos entre los vericuetos de los callejones polvorientos y mal iluminados por algunos postes del alumbrado público, detrás de los camiones aparcados (Ortiz Peña 2013: 18).

Si en la novela de Ronsino lo que predomina es la descripción excesiva y la presencia fantasmal del pasado, en la obra de Ortiz Peña es la pura acción en un devenir sin dirección, en un estado de fuga permanente. Toman la micro a Concepción en variadas ocasiones, visitan bares de mala muerte, se juntan en el bosque, la playa o el cerro. Penco funciona como un pueblo satélite de la gran ciudad de Concepción, epicentro de la resistencia durante los años de represión. Los niños extremistas miran con suspicacia a los estudiantes de la Universidad de Concepción cuando discuten sobre la lucha del proletariado, el ejemplo de Cuba o el rol de la iglesia en la dictadura. Frente a estos ideales colectivos, Jim tiene sus propias ideas de la rebelión. Muestra su desprecio a los discursos del perdón y reconciliación de la izquierda, y a toda forma de "colectivismo moral": "Renunciamos al ego y sin ego nunca nos vamos a convertir en lo que queremos. Sin libertinaje somos un país en franca decadencia... de los sueños colectivos pasamos a la amnesia masiva" (Ortiz Peña 2013: 45). En su lugar, el devenir de la rabia y el deseo individual se concibe como punto de escape al adormecimiento colectivo. El cineasta se pregunta:

¿Cómo uno se hace extremista? ¿En calidad de personaje iluminado que viene a cumplir el plan pre-establecido por dios? ¿En calidad de producto directo de una época, de la práctica política de su coyuntura histórica? Vaya uno a saber. En lo que a mí respecta, de niño siempre me gustó repartir bala. En defensa de mi propia

\footnotetext{
${ }^{6}$ Ver Amaro (2014).
} 
vida, claro. Y la de mis amigos. La demás gente siempre me importó un comino (Ortiz Peña 2013: 22).

Ser extremista aparece como un instinto primario que no responde ni a un llamado profético ni a la racionalidad del discurso histórico, sino que surge de una actitud defensiva individual y de la amistad. La amistad se transforma en el eje afectivo del relato, y la conexión más poderosa, desplazando los relatos de filiaciones que priman en las novelas de la postdictadura. Los amigos de infancia se encuentran en la "esquina de siempre", un lugar que funciona fuera de los límites de la casa y de la familia, y por ende, de sus reglas. Ahí pasan las horas muertas del día fumando, tomando y escuchando música a todo volumen en una actitud desafiante ante los vecinos. Así como la esquina es el punto de intersección entre diversas calles y personas, dentro de la narración misma será el lugar donde se gestan muchos de los actos violentos de la novela. En una dinámica de letargo-conspiración-acción inmediata, esos tiempos improductivos pasan de pronto a un delirio creativo/destructivo alimentado por la rabia al sistema. Junto a la tribu de adolescentes marginales, los personajes se mueven en las sombras guiados por el pulso libertino de la noche, orquestando una obra de deseo fuera de la ley: "Nos metimos en un vagón abandonado a esperar que pasara esa ronda de guardias, pacos o matones. Escuchamos unas voces tranquilas, asustadas. Era un sonido de muchachos pobres, de nuestra juventud precaria; era la conversación caótica de los fumadores de marihuana, de los tomadores, de los calientes, de los hambrientos" (Ortiz Peña 2013: 127). Los representantes del sistema represivo siguen siendo la fuerza policial y militar, aunque personificada en el enemigo de infancia Pancho, con quien protagonizan una serie de escenas violentas e inverosímiles.

En los robos, huidas y enfrentamientos la narración adquiere una velocidad inusitada; es el ritmo del caos, del derroche en el que se entrelazan bailes, sexo, peleas, explosiones y balaceras. Un ejemplo es la persecución interminable tras el asalto del Banco Estado, que toma la estética de películas clase B y de un videojuego:

Semáforo tras semáforo, esquina tras esquina los dejábamos atrás para que reaparecieran a la siguiente. En un semáforo que cambiaba a amarillo Ángelo disparó al azar. Bum. La vieja gasolinera voló. Las llamas crepitaban por mi espejo retrovisor. Entre las nubes oscuras y el rojo flameante aparecieron de nuevo los opresores en su moto (Ortiz Peña 2013: 107).

A medida que avanza la novela los principios de la verosimilitud son minados, transformándose en una narración de lo improbable que de algún modo asume la imposibilidad de cambiar el sistema. El desenlace de la novela con los personajes defendiéndose a punto de ametralladoras y granadas en la casa del bosque rodeada de fuerzas policiales y militares lideradas por Pancho, deja en evidencia que el relato parece fruto de una imaginación infantil que quebranta las leyes internas del relato. Ángelo, el extremista, se transforma en una suerte de Rambo: "Saltó a la ventana, echó abajo de un solo movimiento 
los vidrios despedazados, apuntó y como si estuviera jugando tumbó a dos monigotes con la vieja escopeta. Tas. Tas. La recargó, limpió el cañón con el puño y volvió a apuntar. ¡Tas! ¡Tas! Los otros corrían para protegerse, pero no alcanzaron a salvarse y cayeron" (Ortiz Peña 2013: 138). La aparición del cuaderno escolar en medio del arsenal de armas deja en evidencia que aquella imaginación infantil proviene de la mente de Jim, y que esa historia ya fue contada. Mientras el cineasta corre cerro abajo para salvarse de la muerte, revive un episodio infantil con Jim cuando escapaban aterrorizados de los militares en una chacra: "Yo era ese mismo nińo: el tiempo daba vueltas en redondo. Nada cambiaría nunca" (Ortiz Peña 2013: 142), lo que hace alusión a una violencia que perdura más allá de los personajes.

De acuerdo a Slavoj Žižek, habría una diferencia entre la violencia subjetiva, representada en esta novela por los actos vandálicos o la represión de fuerzas militares y del orden, y lo que llama la violencia objetiva o sistémica que es parte constitutiva del sistema capitalista y funciona dentro la normalidad de la vida cotidiana de la democracia, "sin un opresor directo" (Žižek 2009). El entorno de Penco, rodeado de bosques de eucaliptus y pinos e invadidos por la presencia de los camiones madereros, deja ver los efectos de una modernización que violenta las formas de vida. En un episodio un camión sin frenos atraviesa la calle principal arrasando con todo y termina chocando con el liceo. La actitud del narrador ante el desenfreno es desafiante, y a diferencia de quienes huyen despavoridos, decide confrontarlo:

...venía un enorme camión azul a toda velocidad...Iba tocando la bocina, contoneándose, expulsando troncos de diámetro grueso por el costado hacia nosotros, saltando entre bache y bache...la gente corrió a protegerse entre los bazares, los supermercados y los almacenes. Mis amigos arrancaron también hacia la esquina, mi esquina. ¡Qué tanto! ¡Para qué arrancar! Y me quedé chantado como un poste del alumbrado público. (Žižek 2009: 67)

Los camiones que sacuden las calles del pueblo son indicios claros de una violencia sistémica encarnada en modos productivos de las últimas décadas, con la intervención de las forestales que sirven a trasnacionales en un pueblo identificado con el ciclo orgánico de su industria local. No es casualidad que la abuela del cineasta piense que su nieto llega en las madrugadas, porque trabaja en los turnos de noche de la fábrica, como lo hicieron sus padres y abuelos. Asimismo, la figura del camión representa para muchos el símbolo del libre mercado, al cerrar las líneas ferroviarias de carga y dejar la distribución en manos de empresas privadas. Eso sin contar el rol que tuvieron en la caída del gobierno de Allende con el histórico bloqueo. A su vez, las persistentes imágenes sonoras que emergen en el relato construyen la dimensión afectiva del paisaje productivo de Penco, como el pito de la fábrica de loza, las olas del mar y los camiones rugiendo: "Nos quedamos en silencio, escuchando los portazos de las casas, el ruido del transporte público, de los escolares y de los camiones que daban inicio a esto que llamamos patria." (Ortiz Peña 2013: 24); "el pueblo seguía igual; pasaban los camiones enfurecidos a más de cien por hora por todo el centro, haciendo retumbar el 
piso. Las casas y los puestos comerciales temblaban. El pavimento agrietado. Parches y parches de asfalto" (Ortiz Peńa 2013: 27). De algún modo estas imágenes no solo cumplen el rol de locación para las acciones, sino que tienen una existencia autónoma en el relato que dejan percibir la hostilidad inherente al territorio del pueblo, y que parece ir más allá de lo humano.

\section{Palabras al cierre}

Ya sea desde la violencia de la descomposición de cuerpos y vidas en La descomposición, como de la celebración festiva de la destrucción violenta en Niños extremistas, ambas novelas reconfiguran el espacio del pueblo en el presente en un diálogo dinámico tanto con el canon literario como con las estéticas del presente. Desde su escritura en provincia, ambas novelas desmantelan las dicotomías fundacionales de la historia de la nación ensayando un relato donde la modernización histórica y la economía neoliberal actual adquieren dimensiones barbáricas. Mientras en Ronsino el diálogo con la imaginación cultural del pueblo se vuelve materia metarreflexiva en torno a los relatos sobre la pampa y su dicotomía heredada, en la novela de Ortiz Peña, la representación literaria del pueblo va en contra de la tradición, al sacudir su característica normalidad aletargada a partir de la mirada del forastero que vuelve a su hogar desde la ciudad. En ambos casos la ficción permite una reexaminación y reescritura de los relatos tradicionales de la historia y abre un espacio para la inclusión de imaginarios en provincia más diversos.

Cada novela en su propia apuesta estética deja ver la imposibilidad de crear un relato del pueblo que dé cuente de la violencia sistémica del período democrático de los noventas, más allá o acá de los acontecimientos visibles: asesinatos, vandalismo u opresión, por un lado, o de los efectos del capitalismo en las formas de vida. En ambas novelas la violencia subjetiva, en los términos de Žižek, nunca esconde del todo la violencia objetiva - muchas veces es la consecuencia de la escritura misma - que determinan estos asentamientos liminales. Es, en definitiva, esa pulsión cotidiana la que marca el ritmo del lenguaje minucioso de Ronsino y del festín hipérbolico de Ortiz Peña, para darle una forma a eso indeterminado que habita la esquina de la historia del pueblo provincial. En esto la diferencia entre las dos novelas es notable: ese festín dinámico y violento de Niños extremistas es acaso una forma más radical de enfrentar la violencia objetiva que el decaído festejo de un cumpleaños marcado por el deterioro. Pero en ambas novelas -ya sea por el lenguaje de la descomposción, ya sea por el lenguaje del desacato- el pueblo chico se vuelve ya no el espacio de la letargía sino un lugar privilegiado desde el cual intervenir en los intersticios simbólicos de la nación. Se trata, volviendo al concepto de Laura Demaría, de un modo de mirar, de situarse en un "entremedio, un claroscuro, un fogonazo que sale de las grandes narrativas dicotómicas que han poblado los relatos metafísicos argentinos [y podríamos decir chilenos]" (Demaría 2014: 440). Como fuerza desestabilizadora ambas novelas rompen con las identidades estancas vinculadas a la periferia provincial, visibilizando la falla, la falta de dirección, la pulsión violenta y deseante inherente al territorio que rompe las fronteras entre el yo y los otros. 


\section{Obras CiTADAS}

Amaro, Lorena. 2014. "Formas de salir de casa, o cómo escapar del Ogro: relatos de filiación en la literatura chilena reciente". Literatura y Lingüistica 29: 96-109.

Bengoa, José. 1990. Historia Social de la Agricultura Chilena. Santiago: Ediciones Sur.

Correa, Sofía et al. 2001. Historia del siglo XX chileno. Santiago de Chile: Editorial Sudamericana.

De Leone, Lucía. 2016. "Imaginaciones rurales argentinas: El campo como zona de cruce en expresiones artísticas contemporáneas”. Cuadernos de literatura 40: 181-203.

Demaría, Laura. 2014. Buenos Aires y las provincias. Relatos para desarmar, Rosario: Beatriz Viterbo Editora.

Espinosa, Patricia. 2013. "Niños extremistas". Las Últimas Noticias, 30 de Agosto.

Gallego Cuiñas, Ana. 2016. "La novísima novela argentina del siglo XXI: Lenguaje y vida". Romance Notes 56(1): 143-154.

Giorgi, Gabriel. 2014. Formas comunes: Animalidad, cultura, biopolitica. Buenos Aires: Eterna Cadencia.

Guerra, Juan José. 2015. "Alegoría de la ruina en la narrativa argentina reciente: La descomposición de Hernán Ronsino y Bajo este sol tremendo de Carlos Busqued”. Estudios de Teoria Literaria 4(8): 87-99.

Latorre, Mariano. 1953. Autobiografía de una vocación / Algunas preguntas que no me han hecho sobre el criollismo. Santiago: AUCH.

Montaldo, Graciela. 2010. El cuerpo de la patria: espacio, naturaleza y cultura en Bello y Sarmiento. Alicante: Biblioteca Virtual Miguel de Cervantes.

Moyano, Daniel. 2018. "Los exilios de Juan José Hernández". In: Juan José Hernández, "La señorita Estrella" y otros cuentos. Buenos Aires: Centro Editor de América Latina. http://www.cervantesvirtual.com/obra-visor/los-exilios-de-juan-jose-hernandez/ html/ba067ca6-a0fc-11e1-b1fb-00163ebf5e63_2.html.

Onetti, Juan Carlos. 1999. Cuentos completos. Madrid: Alfaguara.

Ortiz Peña, Gonzalo. 2013. Niños extremistas. Santiago de Chile: Sangría.

Prieto, Martín. 2006. Breve historia de la literatura argentina. Buenos Aires: Taurus.

Ronsino, Hernán. 2011. "Birabent: La fundación de un pasado”, 2011. http://lopensamos. blogspot.co.uk/2011/02/birabent-la-fundacion-de-un-pasado.html

Ronsino, Hernán. 2014 [2007]. La descomposición. Buenos Aires: Eterna Cadencia.

Salazar, Gabriel et al. 1999. Historia contemporánea de Chile, Tomo II. Actores, Identidady Movimientos. Santiago: Ediciones Lom.

Sarlo, Beatriz. 2012. "Afinidades electivas". En Ficciones argentinas. 33 ensayos. Buenos Aires: Mardulce. 27-31.

Friera, Silvina. 2017. "Me interesan las pequeñas historias de los pueblos". Página 12, Miércoles, 19 de diciembre de 2007.

Žižek, Slavoj. 2009. Sobre la violencia. Seis reflexiones marginales. Buenos Aires: Paidos. 
